\title{
Commentary on Allan Kellehear's "Near-Death Experiences and the Pursuit of the Ideal Society"
}

\author{
Antonia Mills, Ph.D. \\ University of Virginia
}

ABSTRACT: Allan Kellehear's article raised four questions for me: (1) whether the near-death experience (NDE) presents enough data about the nature of a transcendent society for it to be a useful model for earthly societies; (2) the degree to which transcendent societies have to address the practical considerations of a material society; (3) whether NDEs are projections of experiencers' cultural concepts about the nature of the transcendent realm(s); and (4) the kind of hope offered by the growing awareness of the features of Western NDEs. I address these questions by referring to transcendent realm concepts and NDEs in the anthropological literature, particularly that of the North American Indian Prophet Movement.

In his article "Near-Death Experiences and the Pursuit of the Ideal Society" Allan Kellehear compared various Western concepts of utopia with the social order experienced in a transcendent realm by modern, mostly Western people who have come near death and had a neardeath experience (NDE). He concluded that the social order portrayed in near-death experiences offers a glimmer of hope for establishing a better society on earth.

I would like to comment on a number of questions that Kellehear's paper raised: first, the extent to which NDEs give a clear concept of a transcendent society (with the emphasis on society); second, the rela-

Antonia Mills, Ph.D., is Research Assistant Professor in the Division of Personality Studies and Lecturer in the Department of Anthropology at the University of Virginia. Reprint requests should be addressed to Dr. Mills at the Division of Personality Studies, Box 152, Health Sciences Center, University of Virginia, Charlottesville, VA 22908. 
tion of utopian concepts to concepts of heaven (are utopias supposed to be "heaven on earth"?); third, the related question of the degree to which NDEs reflect the concepts of the experiencer's culture about the nature of a transcendent realm (whether portrayed as a single or variegated afterworld, or dichotomized into heaven and hell); and finally, I would like to comment upon the kind of hope that NDEs do present.

\section{To What Extent Do NDEs Portray a Transcendent Society?}

As a sociologist, Kellehear was particularly interested in the concepts of society embodied in NDEs. However, he himself noted that Michael Sabom (1982) and others (Owens, Cook, and Stevenson, 1990) have found that not all recorded NDEs include an experience of going to another realm. In about 30 percent of Sabom's sample of Western NDEs the experiencer had an out-of-body experience (OBE), what Sabom called an autoscopic experience, in which he or she saw his or her body from the vantage point of being outside it, but did not have the experience of going on to another realm. Of the NDEs that did, the experience was typically of meeting a messenger/guide/religious figure/being of light and/or deceased relatives. Sometimes the setting in which these meetings took place could be construed as being in a transcendent society but, as Kellehear noted, often these meetings took place in sylvan settings, or in nebulous places such as clouds. Such transcendent NDEs do not tell us much about the nature of a transcendent society per se.

Furthermore, a characteristic feature of NDEs is reaching a barrier beyond which one cannot go; for if one did, one could not come back. Therefore the near-death experiencer is not in a position to portray what the society (or absence of society) on the other side of that barrier might be like. One would not expect travelers who only came into foreign airports or landing strips, were met by a welcoming committee, and then sent back, to tell us much about the qualities and characteristics of the societies behind the airports and landing strips. The same applies to NDEs. Indeed, if a graduate student was intending to write a thesis on the nature of various societies, Western and nonWestern, on the basis of visits to those societies, and found him- or herself prevented from getting past the welcoming committee at the airport or landing strip, one would expect the student to change the topic of the thesis. One can legitimately wonder whether NDEs provide enough of 
a picture of a transcendent society to warrant trying to flesh out the features of such a society on the basis of NDEs alone. However, those who have transcendent NDEs often describe an overwhelming sense of understanding and intense feelings of love and connectedness, which they strive to implement in their lives after their return. I return below to the question of how society in the sense of social relationships may be altered by our knowledge of NDEs.

\section{The Relation of Utopias to Concepts of Heaven}

Kellehear, citing J.C. Davis (1984), noted that there are a variety of different types of utopian societies Western thinkers have constructed, and then asked which type of utopian society most closely corresponded to the features of the transcendent realm as depicted in NDEs. For the reasons given above, I am not sure that NDEs tell us much about the nature of the society that can be presumed to lie beyond the threshold the near-death experiencer has reached. If they did, what relevance would that have to their correspondence to the various types of utopias that have been mentally constructed? Was Kellehear implying that utopian concepts reflect concepts of the nature of a transcendent world? Or vice versa?

As a psychological anthropologist, I would like to point out that all (or almost all) societies have a concept of a transcendent world or worlds, but not all societies develop utopian concepts. Since utopian concepts typically embody concepts of governance of society, it is state societies that typically create utopias. Indeed, many utopias yearn for the simplicity and egalitarian conditions perceived in the societies of the noble savage.

Geoffrey Parrinder (1956) and Gananath Obeyesekere (1980) have noted that most tribal (or non-state) peoples portray the transcendent realm as a single society that closely resembles their earthly society. They view their own society and world as desirable and expect to return to it after a sojourn in a transcendent or otherworldly realm. Parrinder called these tribal societies "life-affirming," in contrast to Hindu, Buddhist, Judeo-Christian and Moslem societies, in which the goal is to attain some form of other-worldly salvation, with or without the benefit of repeated earthly lives in which to reach perfection. In most non-state societies one does not expect to be judged in the transcendent realm (or in one's future life back on earth) on the basis of one's performance in the previous life. By contrast, the major world 
religions portray the afterworld as divided into one or more realms of heavenly reward or hellish punishment.

All the utopias with which Kellehear dealt were Western concepts of utopia. One useful classification of (Western) utopias distinguishes between attempts to present an idealized blueprint of an ideal or more perfect society that admittedly exists nowhere (the etymology of the word utopia indeed means "no where"), and practical or experimental utopias. The transcendent world, by contrast, is typically believed to exist somewhere, or elsewhere, and indeed to be real, perhaps the reality from which the shadow world we take for real comes. Utopias, then, can exist in a mental, abstract plane, or be practical, intentional attempts to establish a society that offers better conditions than the contemporary society.

Both the theoretical and the applied utopian models for society are conceived as improvements on the social conditions in the author's existing society, and both consider how to meet the members' material needs of food, shelter, clothing. By contrast, in most societies' concepts of a transcendent or heavenly society, bodies are considered more ethereal, and earthly needs are portrayed as automatically fulfilled; one need only think of the desired food and it appears, or, to use a Beaver Indian example, think of the raiment one wants to wear (and indeed the form of the "physical" body one wants to have) in order to take on that form and clothing.

Thus in many depictions of the "Happy Hunting Ground," a common North American concept of the world one goes to after death, people may sport at hunting, but the game is always plentiful and one's wish for meat fulfilled. This obviously contrasts to conditions on earth (Beaver Indian men were successful in only one out of four times they went to hunt, during a period of a year in which Robin Ridington and I tabulated their efforts and success). In other words, the conditions of life in earthly utopias are quite different from those depicted in many societies' concepts of a transcendent afterworld.

The most well known of the Greek utopias, Plato's Republic, was certainly not based on the older Greek Olympian or Stygian transcendent worlds. Many early Greek utopias were based on the myth of Atlantis, a lost but earthly continent. Most modern Western utopian constructs, from Thomas More's in 1516 on, have been created in response to the discovery of a brave new earthly world, stimulated by the concept that a vast and virgin territory, often depicted as "a sylvan paradise," was waiting for the establishment of a more perfect society. From the first Pilgrims who came to North America to the present, the 
New World has continued to be the site of many intentional attempts to found a society or subsociety on the basis of freedom from some form of societal oppression in the societies of Europe. Again, such utopias were seldom based on concepts of the nature of heavenly worlds.

The irony is that Europeans establishing such utopian societies in the New World with few exceptions gave themselves the freedom to disregard the fact that the American continents were already populated with native societies that wanted to remain living in the same sylvan setting. The natives of North America responded to the invasion of their territory by Europeans (in part) by a series of Prophet Movements in which the religious leader would apparently die, then revive, and upon revival instruct his society from the vantage of the illumination he had received in a transcendent realm-in other words, from an NDE (Mills, 1982). These NDEs of native religious leaders typically included visions of the future, a feature that Kenneth Ring (1984) has noted as occurring in a small subsample of Western NDEs.

After the decimation of the buffalo from the plains and the spread of European disease, numerous North American Indian societies adopted the Ghost Dance (into which the Prophet Dance had evolved). The Ghost Dance was designed to give not only the shamans or religious leaders, but all participants, the experience of traveling to a transcendent realm and being reunited with their deceased relatives in a land where the buffalo still roamed and there were no Europeans (Mills 1982; Mooney 1896/1965). The Ghost Dance, then, produced group NDEs. The experience was so vivid to the practitioners that they hoped that if they practiced it fervently and frequently enough they would be able to bring about a transformation of this earth into the transcendent realm experienced while in trance. We all know the sad story of the white authorities' misunderstanding of this poignant group native NDE: fearing that the Indians meant to achieve a land without whites by massacring them, they outlawed the dance, and when they found the Sioux still practicing it, the United States Militia responded with the Massacre at Wounded Knee. Thus they transformed the NDE into a true death experience.

A further irony was contained in the fact that Frederick Engels (1902) established his outline for a society with less oppression of the masses or of laborers on the basis of Lewis Morgan's (1877/1971) portrayal of primitive communism, which Morgan (1851/1901) drew from his observations of the Iroquois, one of the first North American groups to be missionized and one of the first to respond with a prophet movement. 


\section{The Relation of NDEs to Cultural Expectation of the Nature of a Transcendent Realm}

One of the questions touched upon by Kellehear but so far not adequately studied is the relation between cultural expectation of the afterworld state and the experience of it by people who come close to death, or apparently die and then revive. Kellehear noted that in Dorothy Counts' (1983) accounts of Melanesian NDEs, the subjects experienced villages like the ones they knew in their society, rather than the cities described by some Western experiencers; but he did not explore the question of whether there is more to NDEs than cultural projection of expectation onto an otherworld dimension.

I have noted many NDE accounts in the ethnographic literature of North American Indians. Unfortunately, to date we do not have a systematic cataloguing of NDEs in all cultures and continents. When such a compendium is made it will be interesting to see to what extent the depiction of the transcendent world in NDEs corresponds to the society's culturally accepted concept of the afterworld. It will also be interesting to see how stable the features found in Western NDEs are in the full range of cultural contexts. I return to a few questions related to the presence or absence of specific traits in different cultures below.

One of the most significant impacts of NDEs in the West is the concept that death is not frightening. The Judeo-Christian portrayal of a heaven/hell dichotomy suggests that many, or at least "bad" or "wicked" people, go to a frightful and painful place after death where they experience eternal hellfire and damnation. As Max Weber (1958) has pointed out, the Protestant ethic was an attempt to minimize the fear of a negative judgment after death, based on the awareness that few people are saints and assured of salvation. The Western cultural expectation that many people will be found wanting and will not achieve a blissful place after death has not been supported by modern Western NDEs. On the contrary, all NDE researchers report that most Western people who have an NDE experience a sense of well-being, peace, joy, and cosmic unity (Greyson 1985; Moody 1975; Owens, Cook, and Stevenson, 1990; Ring 1984; Sabom 1982). Bruce Greyson (1981) further reported that people who attempt suicide (often construed as the ultimate cultural no-no) and who then have an NDE report just as positive experiences as people whose NDE came as a result of accidents, operations, or fatal illness. In other words, Western NDEs are not simple confirmations of cultural expectation. Is this because, as Carol Zaleski (1987) suggested, modern NDEs express a modern vision influenced by the spiritualist movement and modern physics? Is tor- 
ture less prominent because torture is less condoned in the modern world than in the medieval? The transformative power of unbidden NDEs suggests that something beyond cultural projection is taking place, but further research is necessary to determine the impact of cultural construction on NDEs.

\section{The Kind of Hope that NDEs Present}

As Kellehear himself noted, the significant aspect of an NDE (at least among North American experiencers) is not the portrayal of the type of political society in a transcendent realm that could be applied to earth, but the quality of social relationships, the feeling of wellbeing and calm imparted there, and the striking diminution of the fear of death. A positive feeling-tone tends to characterize NDEs whether they are of the OBE or autoscopic variety or include arrival at the threshold of a transcendent realm and interaction with figures/ relatives there. There is no indication that that feeling is a result of the sociological features of the transcendent society per se.

It is this largely positive experience of modern NDEs that has captured the imagination of this generation. However, the experience of light and beings of light that Greyson (1985) and Justine Owens, Emily Cook, and Ian Stevenson (1990) have found to typify some types of NDEs, are not universally reported. They are not a characteristic of the NDEs collected in India (Pasricha and Stevenson, 1986). Owens, Stevenson, and Cook's (1990) finding that the experience of light was correlated with being medically close to death, and that subjects whose medical condition was judged less serious were less likely to have the experience of light, may suggest that the absence of the experience of light in India is an artifact of the subjects being medically in less serious condition, and/or the result of fewer of the Indian subjects being brought back from the brink of death by state-of-the-art medical technology available in the United States. Why NDEs in India do not contain more accounts of positive affect is more of a puzzle.

Perhaps one of the reasons positive affect is less noteworthy in the Indian NDEs is because the Indian attitude towards death is different to begin with. I hypothesize that in those societies in which there is a firm belief in reincarnation, there is much less fear of death than in those (Judeo-Christian and Moslem) societies in which the religion traditionally portrayed that people will either go to a heavenly reward, or be tormented in hell. I hypothesize that such a reduced fear of death will already be present in both those societies that believe in reincar- 
nation and do not expect the afterworld state to be a reward or punishment for earthly demeanor (as among the tribal peoples of all continents), and in those Hindu and Buddhist societies that believe that the transcendent sojourn (like the future life) will reflect conduct in previous lives and may contain sojourns in transcendent realms that are appropriately pleasant or hellish.

Certainly the first missionaries who sought to enlighten the natives of North America noted their striking absence of fear of death (Thwaites, 1896). Missionaries also recorded experiences among their native parishioners that were very like NDEs, except that in some instances, the person did not revive in the same body, but returned to earth to be reborn as an infant. In a forthcoming book on Amerindian reincarnation beliefs (Mills and Slobodin, in press), the similarity of visionary NDEs of native Americans, such as that of Black Elk (Neihardt 1932/1961), are compared to the visionary experiences of native Americans who recount dying and being reborn in a new body, such as Thunder Cloud (Radin 1926/1983).

Interestingly, the Amerindian accounts of such experiences did not include the self-reflective reports of feelings of well-being and cosmic unity of Western NDEs, perhaps because North American Indians were not expected to be effusive about describing the emotions of visionary experience; perhaps because the recital of the vision itself was expected to convey the sense of cosmic unity and well being implicitly to the auditors.

Much more research needs to be done to understand whether the positive affect associated with NDEs, particularly with experiences of light present in some NDEs (Owens, Cook, and Stevenson, 1990), is similar to the experiences of shamans and of trance dancers, to some states of meditation, or to other altered states of consciousness. Obviously, much more research needs to be done to ascertain whether consciousness transcends physical or bodily death. Kellehear, like many writers on NDEs, avoided the question of whether NDEs present any evidence for a transcendent reality. Such questions do not lend themselves to simple answers, but they remain important, perennial questions that deserve careful study.

I suspect that NDEs have captured the imagination of the current generation because they do offer hope that such questions can be answered, and may be answered in the affirmative. We can learn something simply from the enthusiasm of the public for the accounts of NDEs. We can, I hope, also learn more about why and how NDEs are such positive and transformative experiences. Before or until these questions are better answered, what can we learn from NDEs to help 
humanity? I suspect the greatest hope lies not in the blueprint for a just society contained in NDEs, but in the message that great positive affect is associated with compassionate relationships, with compassionate rather than punitive or judgmental evaluation. Perhaps if we can learn to evaluate both ourselves and others from such a compassionate vantage point we will come closer to experiencing "heaven on earth."

\section{References}

Counts, D.A. (1983). Near-death and out-of-body experiences in a Melanesian society. Anabiosis: The Journal of Near-Death Studies, 3, 115-135.

Davis, J.C. (1984). The history of utopia: The chronology of nowhere. In P. Alexander and R. Gill (Eds.), Utopias (pp. 1-17). London, England: Duckworth.

Engels, F. (1902). The origin of the family, private property, and the state (E. Unterman, Trans.). Chicago, IL: Charles Kerr.

Greyson, B. (1981). Near-death experiences and attempted suicide. Suicide and LifeThreatening Behavior, 11, 10-16.

Greyson, B. (1985). A typology of near-death experiences. American Journal of Psychiatry, 142, 967-969.

Mills, A. (1982). The Beaver Indian Prophet Dance and related movements among North American Indians. Unpublished doctoral dissertation, Harvard University, Cambridge, MA.

Mills, A., and Slobodin, R. (Eds.). (In press). Amerindian rebirth: Reincarnation belief among North American Indians and Inuit Toronto, Ontario: University of Toronto Press.

Morgan, L.H. (1901). The League of the Ho-Do-No-Sau-Nee or Iroquois. New York, NY: Dodd Mead. (Original work published 1851)

Morgan, L.H. (1971). Ancient society: Or researches in the line of human progress from savagery through barbarism to civilization. New York, NY: New York Labor Press. (Original work published 1877)

Moody, R.A., Jr. (1975). Life after life. Covington, GA: Mockingbird.

Mooney, G. (1965). The Ghost Dance religion and the Sioux outbreak of 1890. Chicago, IL: University of Chicago Press. (Original work published 1896)

Neihardt, J.G. (Ed.). (1961). Black Elk speaks. Lincoln, NE: University of Nebraska Press. (Original work published 1932)

Obeyesekere, G. (1980). The rebirth eschatology and its transformations: A contribution to the sociology of early Buddhism. In W. OFlarety (Ed.), Karma and rebirth in classical Indian traditions (pp. 137-164). Berkeley, CA: University of California Press.

Owens, J., Cook, E.W., and Stevenson, I. (1990). Features of "near-death experience" in relation to whether or not patients were near death. Lancet, 336, 1175-1177.

Parrinder, G. (1956). Varieties of belief in reincarnation. Hibbert Journal, 55, 260-267.

Pasricha, S., and Stevenson, I. (1986). Near-death experiences in India. Journal of Nervous and Mental Disease, 174, 165-170.

Radin, P. (1983). Crashing Thunder: The autobiography of an A merican Indian. Lincoln, NE: University of Nebraska Press. (Original work published 1926)

Ring, K. (1984). Heading toward omega: In search of the meaning of the near-death experience. New York, NY: William Morrow.

Sabom, M.B. (1982). Recollections of death: A medical investigation. New York, NY: Harper and Row. 
Thwaites, R. (Ed.). (1896-1901). The Jesuit Brothers and allied documents. Vol. 1. Cleveland, OH: Burrow Brothers.

Weber, M. (1958). The Protestant ethic and the rise of capitalism. New York, NY: Scribner.

Zaleski, C. (1987). Otherworld journeys: Accounts of near-death experience in medieval and modern times. New York, NY: Oxford University Press. 